\title{
DARK CURRENT MECHANISMS IN BULK GaInNAs PHOTODIODES
}

\author{
W. M. Soong, J. S. Ng, M. J. Steer, \\ M. Hopkinson, and J. P. R. David ${ }^{1}$ \\ Department of Electronic and Electrical \\ Engineering, \\ University of Sheffield, \\ Mappin Street, Sheffield S1 3JD, \\ United Kingdom. \\ ${ }^{1}$ Email: j.p.david@shef.ac.uk
}

\author{
J. Chamings, S. J. Sweeney, A. R. Adams, and \\ J. Allam
}

Advanced Technology Institute, School of

Electronics and Physical Sciences, University of Surrey, Guildford, Surrey GU2 7XH, United Kingdom.

\begin{abstract}
We have grown a series of bulk GaInNAs p-i-n diodes and identified some of the dark current mechanisms present in our devices. With a nitrogen composition of $\sim 4 \%$, the band gap can be reduced to $0.94 \mathrm{eV}$. We also demonstrate that low dark current density is achievable without compromising the absorption and hence quantum efficiency up to $1.4 \mu \mathrm{m}$.
\end{abstract}

Keywords-GaInNAs; GaAs; photodiode

\section{INTRODUCTION}

There is a requirement for opto-electronic detectors that work within the telecommunication window of $1.3 \mu \mathrm{m}$ to $1.55 \mu \mathrm{m}$ for metropolitan applications. $\operatorname{In}_{0.53} \mathrm{Ga}_{0.47} \mathrm{As}$ photodiodes grown lattice-matched on InP substrates are currently the most widely used devices for this purpose. Lately, GaInNAs grown lattice-matched on GaAs substrates has attracted huge interest as it is also possible [1] to cover this wavelength range but on larger and cheaper substrates.

However, increasing the indium and nitrogen compositions to reduce the band gap has resulted in poorer optical quality, at least as far as the emission characteristics [2] are concerned. However, we showed recently that the detection quantum efficiency up to $\sim 1.3 \mu \mathrm{m}$ is not significantly affected as a result of the addition of indium and nitrogen [2]. So far, the published data have generally shown very high dark current densities in diodes fabricated from this material system, and this is attributed to the traps observed in deep-level transient spectroscopy studies [3, 4]. There is a suggestion that large indium and nitrogen compositions concomitant with telecommunication wavelength results in an unacceptably high dark current density in this material system. In this work, we investigate systematically the effect of increasing nitrogen content on the dark currents in GaInNAs p-i-n diodes grown lattice-matched on GaAs substrates.

\section{WAFER STRUCTURES AND DEVICE FABRICATIONS}

We have grown a series of bulk nominally lattice-matched p-i-n GaInNAs wafers on (001) $\mathrm{n}^{+}$GaAs substrates with solid source Molecular Beam Expitaxy. Be and $\mathrm{Si}$ are used as the p- type and n-type dopants respectively while the nitrogen is supplied from a radio frequency plasma source. The $\mathrm{p}^{+}$and the $\mathrm{n}^{+} \mathrm{GaAs}$ cladding layers were grown at $590^{\circ} \mathrm{C}$ with a growth rate of $0.56 \mu \mathrm{m}$ per hour. For the growth of the $\mathrm{p}^{+}$, nominally undoped and the $\mathrm{n}^{+}$GaInNAs layers, a growth rate of $0.5 \mu \mathrm{m}$ per hour and a growth temperature of $450^{\circ} \mathrm{C}$ were used. The much lower growth temperature used for the GaInNAs layers was to encourage nitrogen incorporation into the GaInNAs layers [5]. In addition to the three wafers reported in [2], we have grown another bulk $\mathrm{p}-\mathrm{i}-\mathrm{n}$ GaInNAs wafer in order to reduce the bandgap energy to $\sim 0.94 \mathrm{eV}$.

Table I shows the structure details of our GaInNAs wafers which are all notionally similar except for the indium and nitrogen compositions. The doping concentration of the $\mathrm{p}^{+}$and the $\mathrm{n}^{+} \mathrm{GaAs}$ cladding layers were nominally doped at $2 \times$ $10^{18} \mathrm{~cm}^{-3}$ as were the thin $\mathrm{p}^{+}$and $\mathrm{n}^{+}$GaInNAs layers that sandwich the undoped GaInNAs i-region. X-ray rocking curves show that the lattice mismatch is low in the bulk GaInNAs wafers (values for wafer A, B and C were reported in [2]). The nitrogen contents are found to be $1,3.2,3.8$, and $4 \%$ for wafers $\mathrm{A}, \mathrm{B}, \mathrm{C}$ and $\mathrm{D}$, respectively.

TABLE I. LAYER STRUCTURES OF BULK GaInNAs WAFERS

\begin{tabular}{|c|c|c|}
\hline \multirow{2}{*}{ Layer } & Nominal layer thickness \\
\cline { 2 - 3 } & Wafer $\boldsymbol{A}$ & Wafers $\boldsymbol{B}, \boldsymbol{C} \boldsymbol{\&} \boldsymbol{D}$ \\
\hline $\mathrm{p}^{+} \mathrm{GaAs}$ & $1000 \mathrm{~nm}$ & $500 \mathrm{~nm}$ \\
\hline $\mathrm{p}^{+} \mathrm{GaInNAs}$ & $200 \mathrm{~nm}$ & $50 \mathrm{~nm}$ \\
\hline $\mathrm{i}-\mathrm{GaInNAs}$ & $1000 \mathrm{~nm}$ & $400 \mathrm{~nm}$ \\
\hline $\mathrm{n}^{+} \mathrm{GaInNAs}$ & $200 \mathrm{~nm}$ & $50 \mathrm{~nm}$ \\
\hline $\mathrm{n}^{+} \mathrm{GaAs}$ & $1000 \mathrm{~nm}$ & $300 \mathrm{~nm}$ \\
\hline $\mathrm{n}^{+} \mathrm{AlAs}$ & $100 \mathrm{~nm}$ & $100 \mathrm{~nm}$ \\
\hline $\mathrm{n}^{+} \mathrm{GaAs}$ & $200 \mathrm{~nm}$ & $200 \mathrm{~nm}$ \\
\hline \multicolumn{3}{|c|}{$\mathrm{n}^{+} \mathrm{GaAs}$ substrate } \\
\hline
\end{tabular}

The wafers were fabricated into $p$-i-n mesa diodes with standard photolithography and wet chemical etching methods. $\mathrm{Au} / \mathrm{Zn} / \mathrm{Au}$ and $\mathrm{In} / \mathrm{Ge} / \mathrm{Au}$ were used to form ohmic p-type and n-type metal contacts, respectively. Figure 1 shows the schematic diagram of the fabricated bulk GaInNAs p-i-n mesa diodes of different sizes, which are 400, 200, 100, and $50 \mu \mathrm{m}$ in diameter. The grey regions are the p-type $\mathrm{Au} / \mathrm{Zn} / \mathrm{Au}$ top metal contacts. For mesa diodes of diameter $400 \mu \mathrm{m}$ and 
$200 \mu \mathrm{m}$, the annular top contacts form the optical windows to allow light access for optical measurements.

The room temperature bandgap energies of the devices were determined by electroluminescence measurements. With forward current injection of $64 \mathrm{~A} / \mathrm{cm}^{2}$ in the measurements, wafers $\mathrm{A}, \mathrm{B}, \mathrm{C}$, and $\mathrm{D}$ exhibited bandgap energies of 1.28 , $1.04,0.97$, and $0.94 \mathrm{eV}$, respectively.

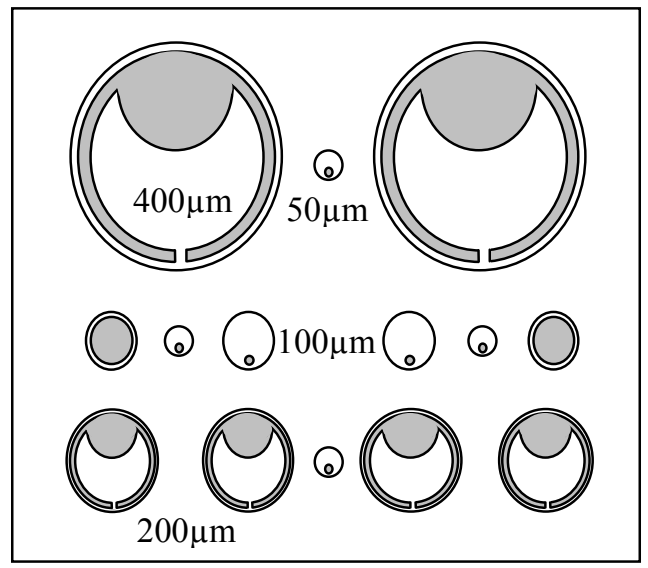

Figure 1. Schematic diagram of the fabricated bulk GaInNAs p-i-n mesa diodes with diameters of $400,200,100$, and $50 \mu \mathrm{m}$. The grey regions are the p-type $\mathrm{Au} / \mathrm{Zn} / \mathrm{Au}$ metal contacts.

\section{RESULTS AND DISCUSSIONS}

Figure 2 compares the room temperature forward current density-voltage curves of wafers A, B, C and D. The ideality factor is $\sim 1.5$ over the linear region shown in Figure 2 for all wafers. At higher bias voltage, the experimental dark current densities deviate from the linear behaviour, suggesting the presence of series resistance. For a given forward bias, the forward dark current density increases with the nitrogen content. The significantly lower forward dark current density of wafer A could be due to its much wider bandgap compared to the other three wafers.

Figure 3 compares the room temperature reverse dark current density-voltage characteristics of wafers B, C, and D. Device reverse dark currents of wafer A were lower than the measurement setup sensitivity so no reliable current density was obtained. In Figure 3, the dark current density increases with nitrogen content. This can be detrimental to photodiode operation when the wavelength is pushed beyond $1.3 \mu \mathrm{m}$ by adding more nitrogen. Current density-voltage characteristic reported by Loke et al [4] is also included in Figure 3 because it was obtained from a wafer similar in structure and bandgap energy to our wafers $\mathrm{B}, \mathrm{C}$ and $\mathrm{D}$. Yet they reported much higher reverse current density-voltage results.

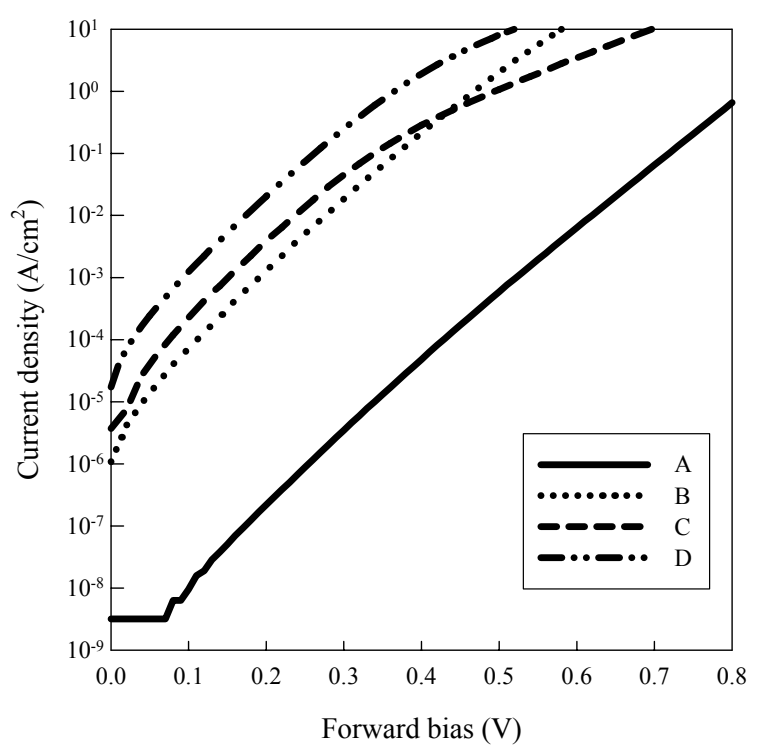

Figure 2. Room temperature forward dark current density-voltage characteristics of bulk GaInNAs p-i-n mesa diodes with nitrogen content from device A to D.

From the electroluminescence measurements, the optical emission quality is deteriorating with nitrogen content [2]. Interestingly, Figure 4 shows that the room temperature photocurrent versus wavelength responses of the GaInNAs p-i$\mathrm{n}$ diodes remain approximately constant up to the absorption edge of $\sim 1.4 \mu \mathrm{m}$, irrespective of the nitrogen content. This demonstrates that photon absorption is not compromised by the addition of the nitrogen, unlike the behaviour seen in the optical emission. This is not surprising since the photocurrent depend primarily on the thickness of the GaInNAs, its light absorption coefficient at a particular wavelength, and the ability to extract the photogenerated carriers via the doped contact layers. Non-radiative centres or growth defects is thus unlikely to affect photon absorption.

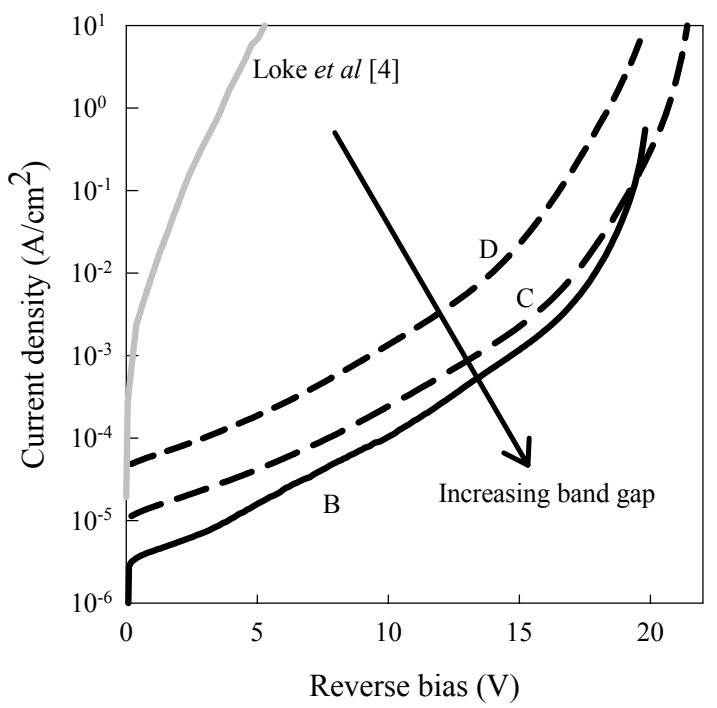

Figure 3. Room temperature current density-voltage data of GaInNAs diodes of varying band gap (dark lines) and those from [4] (grey line). 


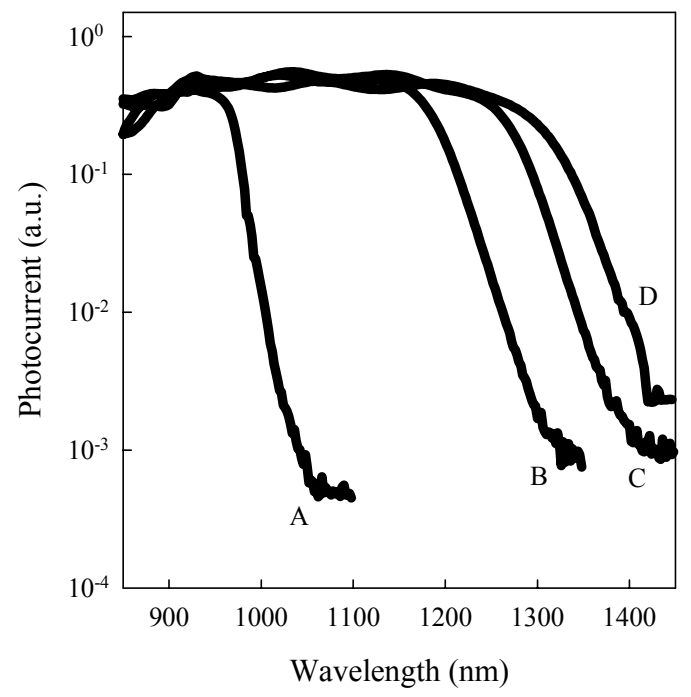

Figure 4. Room temperature photocurrent of GaInNAs diodes when reversebiased at $2 \mathrm{~V}$. Wafers $\mathrm{A}, \mathrm{B}$ and $\mathrm{C}$ have been previously reported in [2].

Figure 5 shows the temperature dependent reverse dark current density-voltage of wafer D. At low temperature, accurate dark current density at reverse bias from $0 \mathrm{~V}$ to $9 \mathrm{~V}$ could not be obtained from the devices due to limitation of the measurement setup. Arrhenius plot of dark current density (inset) at reverse bias voltages of 1 and $5 \mathrm{~V}$ shows an activation energy of $\sim 0.5 \mathrm{eV}$, which is half of the band gap in sample $\mathrm{D}$ $(0.94 \mathrm{eV})$. This suggests the presence of a generationrecombination current mechanism [6]. At high reverse bias voltage, the dark current density appears to be less sensitive to changes in temperature. This could be attributed to the classical band-to-band tunneling mechanism that is commonly observed in narrow bandgap semiconductor materials [6].

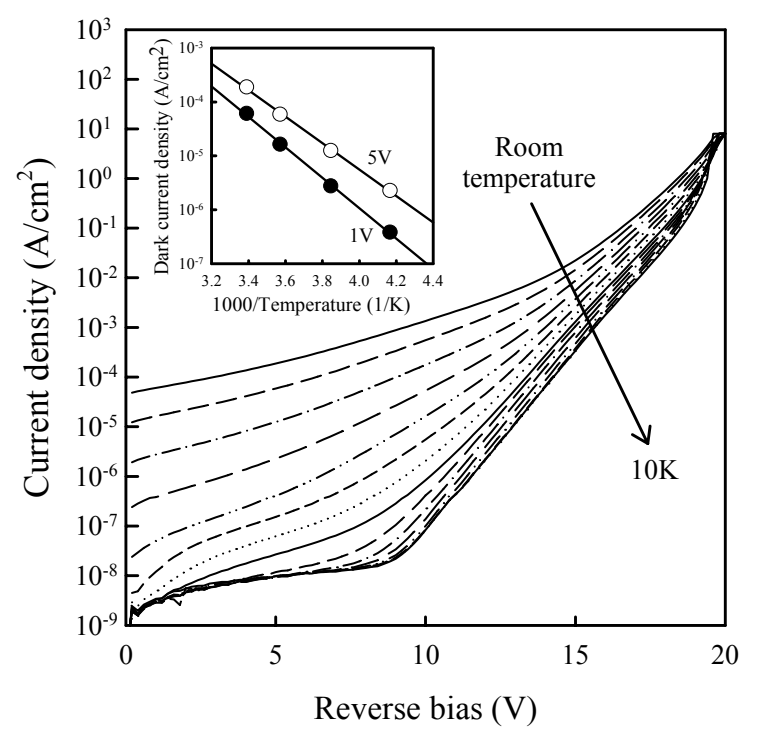

Figure 5. Temperature dependence of the reverse dark current densityvoltage of wafer D, which has a room temperature bandgap of $0.94 \mathrm{eV}$. Arrhenius plot for current density (inset) at low bias voltages shows an activation energy of $\sim 0.5 \mathrm{eV}$.
Figure 6 shows the dark current density of GaInNAs wafers versus reverse bias voltage at $77 \mathrm{~K}$. Also included is a latticematched bulk p-i-n InGaAsP on InP substrate with a bandgap energy of $0.94 \mathrm{eV}$ and an i-region thickness of $0.4 \mu \mathrm{m}$. The dark current density of the GaInNaAs wafers decreases with the bandgap energy for a given reverse bias. At high reverse bias but prior to the onset of avalanche breakdown, the bulk pi-n GaInNAs wafers exhibit exponential increase in dark current density with bias. Such behaviour differs from the typical band-to-band tunneling current-voltage characteristics.

Comparing wafer D and the InGaAsP wafer, both of which have similar bandgap energy, they exhibit similar dark current density from $13 \mathrm{~V}$ onwards. For the InGaAsP wafer, the reverse dark current density is dominated by band-to-band tunneling current mechanism. At below $13 \mathrm{~V}$, wafer $\mathrm{D}$ shows higher reverse dark current density than the $\mathrm{InGaAsP}$ wafer. This implies the presence of an unknown dark current mechanism that dominates in the mid voltage range before the band-toband tunneling current mechanism comes into effect at the higher reverse bias voltages.

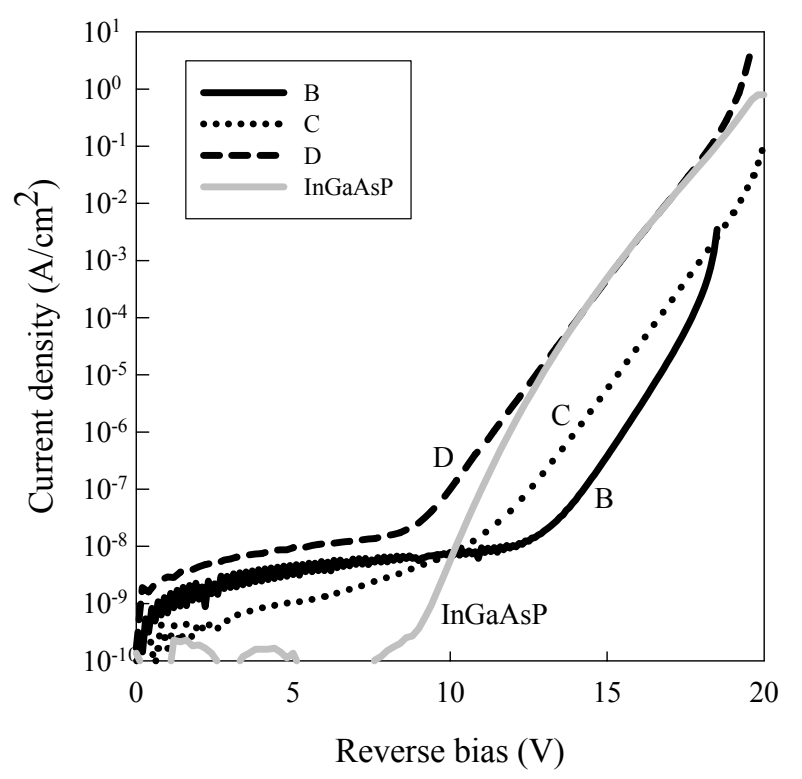

Figure 6. Reverse dark current densities versus reverse bias voltage of the GaInNAs diodes at $77 \mathrm{~K}$.

\section{CONCLUSIONS}

We have demonstrated that relatively low dark current density can be obtained without compromising the photoabsorption in bulk p-i-n GaInNAs devices up to $\sim 1.4 \mu \mathrm{m}$. The high dark current observed at room temperature and low biases is thought to be due to a generation-recombination mechanism. Further investigation into the dark current characteristics at the high reverse bias range could lead to a better understanding on the overall dark current mechanisms in GaInNAs and thus further suppressing the total dark current. 


\section{REFERENCES}

[1] M. Kondow, "GaInNAs: A novel material for long-wavelength-range laser diodes with excellent high-temperature performance”, Jpn. J. Appl. Phys. vol. 35, pp. 1273-1275, Part 1, No. 2B, 1996.

[2] J. S. Ng, "Long wavelength bulk GaInNAs p-i-n photodiodes latticematched to GaAs", J. Appl. Phys. vol. 101, 064506, 2007.

[3] D. Jackrel, "Thick lattice-matched GaInNAs films in photodetector applications", Semiconductor Photodetector II, Proceedings of SPIE, vol. 5726, pp. $27-34,2005$.

[4] W. K. Loke, S. F. Yoon, S. Wicaksono, K. H. Tan, and K. L. Lew, "Defect-induced trap-assisted tunneling current in GaInNAs grown on GaAs substrate”, J. Appl. Phys. vol. 102, 054501, 2007.
[5] E. M. Pavelescu, "Nitrogen incorporation into GaInNAs lattice-matched to GaAs: The effect of growth temperature and thermal annealing", J. Appl. Phys. vol. 98, 083524, 2005.

[6] A. Zemel, and M. Gallant, "Current-voltage characteristics of metalorganic chemical vapor deposition InP/InGaAs $p-i-n$ photodiodes: The influence of finite dimensions and heterointerfaces", J. Appl. Phys., vol. 64 (11), pp. $6552-6561,1988$. 